Neurosurg Focus 23 (3):E1, 2007

\title{
Diagnostic approach to Cushing disease
}

\author{
Bradley A. Gross, B.S., ${ }^{1}$ Stefan A. Mindea, M.D., ${ }^{1}$ Anthony J. Pick, M.D., ${ }^{2}$ \\ James P. Chandler, M.D., ${ }^{1}$ ANd H. Hunt BatJer, M.D. ${ }^{1}$ \\ ${ }^{1}$ Departments of Neurological Surgery and ${ }^{2}$ Endocrinology, The Feinberg School of Medicine and \\ McGaw Medical Center, Northwestern University, Chicago, Illinois
}

\begin{abstract}
$\checkmark$ In Cushing disease, a pituitary corticotroph neoplasm causes secondary adrenal hypercortisolism. This condition has known morbidity and mortality, underscoring the need for an efficient and accurate diagnostic approach. An 11 p.m. salivary cortisol level is a modern, simple initial screening tool for the diagnosis of Cushing syndrome. Confirmation with a 24-hour urinary free cortisol test and/or a low-dose dexamethasone suppression test may subsequently be performed. Patients with repeatedly equivocal results should be reevaluated after several months or undergo a corticotropin-releasing hormone $(\mathrm{CRH})$ stimulation test following low-dose dexamethasone suppression to help rule out pseudo-Cushing states. The presence of low morning serum adrenocorticotropic hormone (ACTH) levels then distinguishes primary adrenal hypercortisolism from Cushing disease and the ectopic ACTH syndrome. Patients with moderate ACTH levels can undergo CRH stimulation testing to clarify the underlying disease because those with an ACTH-independent disorder have blunted subsequent ACTH levels. Once ACTH-dependent hypercortisolemia is detected, magnetic resonance (MR) imaging of the pituitary gland can be performed to detect a pituitary neoplasm. Normal or equivocal MR imaging results revealing small pituitary lesions should be followed up with inferior petrosal sinus sampling, a highly specific measure for the diagnosis of Cushing disease in experienced hands. If necessary, body imaging may be used in turn to detect sources of ectopic ACTH. (DOI: 10.3171/FOC-07/09/E1)
\end{abstract}

\section{KEY WORDS • adrenocorticotropic hormone - Cushing disease • dexamethasone sup- pression test - petrosal sinus sampling}

$\mathrm{C}$ USHING disease, first described by Harvey Cushing in 1912 in his book entitled The Pituitary Body and its Disorders, is the most common cause of spontaneous Cushing syndrome, accounting for approximately two thirds of cases. ${ }^{35,36}$ In this disease, neoplastic corticotroph hypersecretion of ACTH leads to excessive production of cortisol from the adrenal cortex. In contrast to their normal corticotroph counterparts, the neoplastic pituitary cells in this disease are relatively resistant to negative feedback from the resultant hypercortisolism and hence continue to produce excessive ACTH, perpetuating adrenal cortisol hypersecretion. Despite the considerable prevalence of hypertension and obesity in the general population, associated temporal fossa and supraclavicular fullness are somewhat specific findings that should prompt the physician to consider screening for Cushing syndrome. ${ }^{11}$ Other associated symptoms include, but are not limited to, bruising, myopathy, glucose intolerance, and osteoporosis. Notably, the absence of bitemporal hemianopsia is not a strong negative predictive factor for Cushing disease because the majority of patients with this disease have pituitary microadenomas. ${ }^{28}$

Appropriate diagnosis and management of Cushing dis-

Abbreviations used in this paper: $\mathrm{ACTH}=$ adrenocorticotropic hormone; $\mathrm{CRH}=$ corticotropin-releasing hormone; $\mathrm{CT}=$ computed tomography; $\mathrm{MR}=$ magnetic resonance; $\mathrm{UFC}=$ urinary free cortisol. ease is important because the mortality rate in patients with this disease is at least fourfold that in the general population matched for age and sex. ${ }^{42}$ Control of hypercortisolism leads to gradual improvement of bruising, myopathy, central obesity, glucose intolerance and hypertension, and rapid improvement of osteoporosis. ${ }^{25}$ Although the initial presentation of a patient with such a constellation of symptoms is suggestive of Cushing syndrome, most symptoms characteristic of the disease are nonspecific, resting the burden of an accurate diagnosis on an appropriate diagnostic workup.

\section{Diagnosis of Cushing Disease}

Throughout the literature there are examples of imperfections and pitfalls in all available testing methods for Cushing disease. Hence, the diagnosis of Cushing disease is a rigorous process often requiring confirmatory tests at each step and endocrine consultation. A simplified diagnostic approach is delineated in Fig. 1. Beginning with a high clinical suspicion based on discriminatory physical features and/or refractory hypertension, one must initially establish a diagnosis of hypercortisolemia using an 11 p.m. salivary cortisol test. The diagnosis of Cushing syndrome is often confirmed by obtaining several salivary cortisol levels and obtaining a 24-hour UFC level or performing a low- 


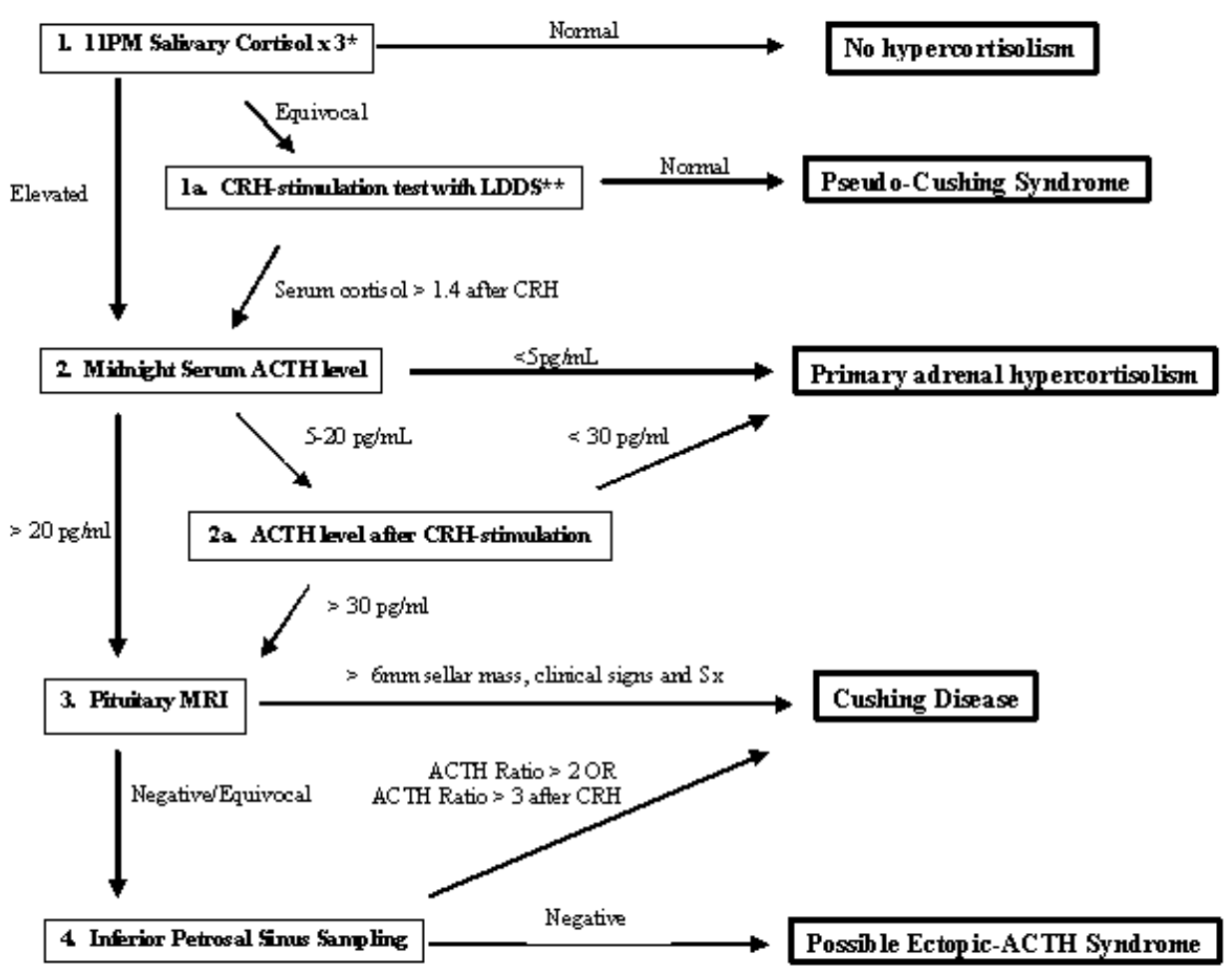

FIG. 1. Schematic showing a simplified diagnostic approach to Cushing disease. LDDS = low dose dexamethasone suppression; $\mathrm{Sx}=$ symptoms. The asterisk signifies that confirmation may be performed with 24-hour UFC or LDDS.

dose dexamethasone suppression test. If these screening tests remain equivocal, the CRH stimulation test following 2 days of low-dose dexamethasone suppression can be employed to distinguish Cushing syndrome from pseudoCushing origins of hypercortisolemia.

Once true Cushing syndrome is diagnosed, it is necessary to determine the cause of the hypercortisolemia. Causes include primary adrenal hypercortisolism and secondary adrenal hypercortisolism due to either a neoplasm of pituitary corticotrophs (Cushing disease) or an ectopic neoplasm autonomously secreting ACTH. A diagnosis of primary adrenal hypercortisolism can be established by the presence of a low morning serum ACTH level. High ACTH levels suggest either the ectopic ACTH syndrome or Cushing disease. Intermediate ACTH levels should be followed by CRH stimulation testing; blunted responses in ACTH levels are diagnostic of ACTH-independent hypercortisolemia. ${ }^{40}$

Once ACTH-dependent hypercortisolemia is identified, MR imaging of the pituitary should be performed. Imaging findings of characteristic hypointense lesions are diagnostic of Cushing disease. Alternatively, if equivocal or negative MR imaging results are present, one should undertake inferior petrosal sinus sampling or, if the clinical suspicion is high, imaging of the neck, chest, and abdomen to search for ectopic sources of ACTH.

\section{Salivary Cortisol}

Given that elevation of late-evening cortisol levels can be the earliest and most sensitive marker for Cushing syndrome, ${ }^{12}$ measurement of serum or salivary cortisol levels at this time may initially prove more effective than measuring 24-hour UFC or attempting a low-dose dexamethasone suppression test. Despite the fact that midnight serum cortisol levels greater than 7.5 are highly specific (approaching $100 \%$ for patients remaining asleep) and quite sensitive (96\%) for true Cushing syndrome, ${ }^{38}$ reliably measuring serum cortisol levels at such a time is generally tedious and unrealistic, particularly given the fact that the patient should remain asleep through the test to avoid false-positive results. Promisingly, the authors of a recent study showed no significant difference between the sensitivity and specificity of midnight serum and midnight salivary cortisol levels for establishing the diagnosis of Cushing syndrome..$^{39}$ Indeed, the investigators of a larger study of 139 patients revealed a sensitivity of $93 \%$ for a set specificity of $100 \%$ for midnight salivary cortisol levels. ${ }^{37}$ The authors of another study of 63 patients with Cushing's 
syndrome reproduced the same sensitivity and specificity; furthermore, lowering the cutoff level for salivary cortisol to produce a sensitivity of $100 \%$ led to a specificity of 96\%. ${ }^{49}$ Attractively, findings of Raff et al. ${ }^{41}$ have shown that an 11 p.m. salivary cortisol level is equal in efficacy to midnight salivary cortisol levels in terms of sensitivity and specificity for the diagnosis of Cushing syndrome..$^{41}$ Hence, a more convenient "bedtime" 11 p.m. cortisol can be measured. It is generally advisable to collect at least three late-night salivary cortisol samples on 3 different days. Indeed, equivocal results one evening may occur in the setting of pseudo-Cushing states such as depression, sleep apnea, polycystic ovarian syndrome, high physical stress, and chronic alcoholism. Interestingly, normal salivary cortisol levels are often observed on repeated testing in such patients, whereas in those with true Cushing syndrome consistently elevated salivary cortisol levels are typically found..$^{48}$ Importantly, however, physiologically elevated salivary cortisol levels during pregnancy reduce the specificity of a midnight salivary cortisol level test to $75 \%,{ }^{48}$ and salivary cortisol testing may not be readily available. In such events, 24-hour UFC and low-dose dexamethasone suppression tests are necessary in the diagnostic workup.

\section{Twenty-Four-Hour UFC and Low-Dose Dexamethasone Suppression}

Given their imperfect sensitivity and specificity, the relatively more laborious 24-hour UFC and low-dose dexamethasone suppression tests better serve as confirmatory tests in cases of elevated late-night salivary cortisol levels or as clarifying tests in cases with equivocal levels of salivary cortisol.

Albeit tedious, a 24-hour UFC test is useful for confirming the diagnosis of Cushing syndrome. With each 24-hour UFC measurement, urine creatinine should be measured to ensure that the collections are complete; high urine volumes may raise the degree of urinary cortisol secretion. ${ }^{30}$ The authors of some studies have shown that a 24-hour UFC level approaches a sensitivity of $100 \%$ and a population-dependent specificity of 94 to $98 \%$ in diagnosing Cushing syndrome, which is significantly superior to urinary 17-hydroxycorticosteroids (sensitivity $73 \%$ and specificity 94\%)., ${ }^{4,29}$ Interestingly, one study of 30 patients with Cushing syndrome in which the investigators tested the utility of overnight (10 p.m.-8 a.m.) urinary cortisol measurements had a sensitivity of $100 \%$ and a specificity of $97 \%$, potentially underscoring a more convenient approach. ${ }^{5}$

Unfortunately, the aforementioned sensitivities and specificities are not reproducible in all studies. For example, at $100 \%$ specificity in one study, 24-hour UFC had a sensitivity of $53 \%$ for one 24-hour collection and a final sensitivity of $91 \%$ in patients with Cushing disease who underwent multiple 24-hour UFC collections. ${ }^{18}$ The authors of another study reported a sensitivity of $45 \%$ for a specificity of $100 \% .{ }^{38}$ This study also underscored the well-known fact that pseudo-Cushing states can cause falsely elevated 24hour UFC levels. ${ }^{38}$

Based on the premise that adenomatous ACTH-producing pituicytes are less likely to respond to negative feedback from steroids, low-dose dexamethasone suppression testing can serve as a confirmatory measure in the diagnosis of Cushing syndrome. Unfortunately, this approach has fallen out of favor as an initial screening test for Cushing syndrome given the difficulty in setting steroid level cutoffs that give an ample balance of sensitivity and specificity. The classic 2-day low-dose dexamethasone suppression test and overnight 1-mg low-dose dexamethasone test are likely to be falsely positive in pseudo-Cushing states and, furthermore, falsely negative in patients with mild Cushing disease because the patients may have suppressible 8 a.m. cortisol levels. The authors of a recent study employing the 2-day low-dose dexamethasone suppression test (dexamethasone $0.5 \mathrm{mg}$ every 6 hours with subsequent measurement of 8 a.m. urine steroid levels) reported a $69 \%$ sensitivity and $74 \%$ specificity for this test. ${ }^{50}$ The authors of another study showed that $18 \%$ of patients with Cushing disease had 8 a.m. cortisol values less than the typical cutoff of $5 \mu \mathrm{g} / \mathrm{dl}$ after an overnight 1-mg dexamethasone suppression test; furthermore, $8 \%$ had cortisol values less than $2 \mu \mathrm{g} / \mathrm{dl} .{ }^{13}$ Hence, like 24-hour UFC measurements, these tests are better employed as confirmatory measures than for screening alone, and, given the labor-intensive nature of a 2-day low-dose dexamethasone suppression test, it is recommended that 1-mg overnight low-dose dexamethasone suppression tests be performed.

\section{Corticotropin-Releasing Hormone After Low-Dose Dexamethasone Suppression}

Patients in whom results are repeatedly equivocal can undergo retesting after several months or can undergo the highly specific (approaching 100\%) 48-hour low-dose dexamethasone suppression with CRH stimulation test. ${ }^{50} \mathrm{In}$ this test, the patient receives $0.5 \mathrm{mg}$ of dexamethasone every 6 hours for 2 days starting at 8 a.m. followed by CRH $(1 \mu \mathrm{g} / \mathrm{kg}$ intravenously) on the final day at 8 a.m. Serum cortisol is then measured 15 minutes later. Although this test reinforces the low-dose dexamethasone suppression test, it crucially rules out any pseudo-Cushingoid causes of hypercortisolemia because only patients with true Cushing syndrome have sufficiently sensitive adrenal axes to have resultant serum cortisol levels greater than $1 \mu 1 . .^{4.14,50}$ Falsepositive results have been found only in heavily exercising males and patients with anorexia nervosa-two populations that would rarely come under scrutiny for a diagnosis of Cushing disease. ${ }^{7,8}$ Despite its excellent specificity, this test is not used in all patients screened for Cushing syndrome because it is quite expensive and cumbersome.

\section{Serum ACTH Levels}

Once the diagnosis of Cushing syndrome is established, it is necessary to determine whether the hypercortisolism is ACTH dependent or independent. This can be expeditiously established via two or three morning (8-10 a.m.) tests of serum ACTH levels. ${ }^{11}$ It is important to keep collections on ice and promptly deliver them to the laboratory to exclude the possibility of in vitro degradation of ACTH and thus falsely low ACTH levels.

Levels less than $5 \mathrm{pg} / \mathrm{ml}$ suggest the presence of ACTHindependent hypercortisolemia, as would occur in cases of adrenal tumors or in syndromes with ectopic receptors on adrenocortical cells such as gastric inhibitory polypep- 
tide-dependent Cushing syndrome (food-dependent Cushing syndrome) and $\beta$-adrenergic-dependent Cushing syndrome. ${ }^{22}$ Such patients can subsequently undergo thin section $\mathrm{CT}$ or MR imaging to confirm the diagnosis.

Adrenocorticotropic hormone levels greater than $20 \mathrm{pg} /$ $\mathrm{ml}$ suggest ACTH-dependent hypercortisolemia, as would occur in patients with Cushing disease or secondary to an ectopic ACTH-producing tumor. Of note, there is a known positive correlation between ACTH levels and adenoma size in patients with Cushing disease. ${ }^{43,44}$ The values between 5 and $20 \mathrm{pg} / \mathrm{ml}$, although less definitive, tend to suggest ACTH-dependent hypercortisolemia. For rigorous confirmation, patients with these intermediate levels can undergo a peripheral $\mathrm{CRH}$ stimulation test to distinguish ACTH-dependent from -independent Cushing syndrome, as individuals with the latter have blunted resultant ACTH levels $(<30 \mathrm{pg} / \mathrm{ml}){ }^{40}$

\section{High-Dose Dexamethasone Suppression Test}

When an ACTH-dependent origin to Cushing syndrome has been established, it is finally necessary to distinguish whether the ACTH is being produced by the pituitary or an ectopic source. Statistically, the odds of having a pituitary adenoma compared with any other source is 5.5:135,36 However, intuitively it remains necessary to distinguish the small proportion of patients with an ectopic source of $\mathrm{ACTH}$, given the neurosurgical implications of a diagnosis of the former. Interestingly, patients with the ectopic ACTH syndrome are more likely to have acute onset of symptoms, hypokalemia, and relatively higher plasma ACTH levels (mean $210 \mathrm{pg} / \mathrm{ml}$ compared with $78 \mathrm{pg} / \mathrm{ml}$ for Cushing disease). ${ }^{1}$

Traditionally, high-dose dexamethasone has been used to suppress pituitary sources of ACTH and hence serum cortisol levels to help distinguish Cushing disease from the ectopic ACTH syndrome. Two mg of dexamethasone is given every 6 hours for 48 hours, after which urinary cortisol is measured..$^{15}$ Suppression of basal urinary cortisol levels (measured in the initial screening) by $90 \%$ is the oftquoted cutoff for this test. ${ }^{2}$ Unfortunately, the sensitivity of this test is limited by the fact that adequate suppression of ACTH secretion may not occur in some patients with Cushing disease. Indeed, the authors of an authoritative study of 186 patients with ACTH-dependent Cushing syndrome showed a sensitivity of 59\% for this test. The sensitivity improved to $72 \%$ when the additional criterion of $64 \%$ suppression of basal urinary 17-hydroxycorticosteroid levels was added. In both cases in this study, the specificity remained $100 \% .^{2}$ Despite such reports of exceptional specificity, the utility of this test has recently been challenged given the fact that many bronchial carcinoids are known to be suppressible by dexamethasone. ${ }^{26,33}$ In a more recent study, the authors revealed a sensitivity of $81 \%$ and a specificity of $66.7 \%$ for this test, while underscoring the fact that the range of cortisol suppression was 0 to $99 \%$ for the ectopic ACTH syndrome and Cushing disease. ${ }^{1}$ Considering these results and the aforementioned prevalence of Cushing disease in the population of patients with ACTHdependent hypercortisolemia ( $\geq 85 \%$ ), the effectiveness of this test becomes dubious. Indeed, given the surgical implications of a diagnosis of Cushing disease, the decision must rest on a highly specific test. Hence, it is advised that highdose dexamethasone suppression be used more as a confirmatory test, if at all, for the diagnosis of Cushing disease.

\section{Imaging Detection}

Because CT scanning is less sensitive than MR imaging in detecting pituitary adenomas, ${ }^{16}$ pituitary MR imaging is a reasonable initial diagnostic step in patients with ACTHdependent hypercortisolemia. Pituitary adenomas are characteristically hypointense on T1-weighted imaging and remain so following contrast administration, which enhances the remaining normal pituitary gland and stalk. Similarly, however, pars intermedia cysts, epidermoid cysts, abscesses, infarctions, and metastases may also appear as areas of low signal intensity after the administration of contrast material. ${ }^{9}$ A convex contour to the superior surface of the pituitary gland and/or stalk deviation, both originally thought to correlate well with the presence of an adenoma, have been shown to exist in 34 and $13 \%$ of healthy individuals, respectively. ${ }^{16}$

Relying on the characteristic appearance of pituitary adenomas for a radiological/neuroimaging diagnosis, pituitary MR imaging findings may be equivocal in up to half of patients with Cushing disease. Indeed, in one study, five of five patients with macroadenomas were appropriately diagnosed by MR imaging, whereas $51 \%$ of 45 patients with surgically confirmed microadenomas had positive MR imaging findings. Furthermore, in four patients the neuroimaging localization of the tumor was inaccurate. ${ }^{16}$ Considering the fact that the authors of a recent metaanalysis of seven postmortem and three imaging studies involving pituitary adenomas reported a prevalence of $16.7 \%$ for these lesions (14.4\% at postmortem and $22.5 \%$ on imaging), false-positive MR imaging results owing to underlying incidentalomas are plausible as well. ${ }^{9}$ Indeed, the authors of a study involving 70 asymptomatic women ( $83 \%$ of whom were of reproductive age) and 30 asymptomatic men showed a prevalence of $10 \%$ of focal pituitary lesions in each group. ${ }^{16}$ Furthermore, of the additional 57 patients in the study with surgically confirmed Cushing disease, six (11\%) had hypointense lesions identified on MR imaging that did not correspond with the site of the actual adenoma found intraoperatively. ${ }^{16}$ Nonetheless, in patients with ACTH-dependent hypercortisolemia, highly suggestive or relatively large $(\geq 6 \mathrm{~mm})$ pituitary lesions on MR imaging and findings more suggestive of Cushing disease-slightly elevated ACTH and cortisol levels, normal potassium levels, and insidious onset of symptoms-are essentially diagnostic of Cushing disease.

Patients in whom suggestive imaging findings are absent should undergo inferior petrosal sinus sampling to definitively confirm Cushing disease. If the suspicion is high based on signs and symptoms, patients may alternatively undergo imaging to search for ectopic ACTH-secreting neoplasms prior to inferior petrosal sampling. These patients should undergo ${ }^{111}$ In-labeled pentetreotide scanning $^{21,42}$ followed by CT and/or MR imaging of the neck, chest, and abdomen. Hyperintensity on T2-weighted MR imaging is characteristic of these neuroendocrine tumors. Importantly, however, false-positive results can occur, underscoring the need for a clinical suspicion of the ectopic $\mathrm{ACTH}$ syndrome prior to these tests, most often precipitat- 
ed by prior negative imaging and negative inferior petrosal sinus sampling.

\section{Inferior Petrosal Sinus Sampling}

As the venous drainage carrying pituitary-produced ACTH includes the inferior petrosal sinus, sinus sampling is an excellent method by which to distinguish Cushing disease from the ectopic ACTH syndrome. In a landmark study, Oldfield et al. ${ }^{35}$ reported on 246 patients with surgically confirmed Cushing disease (215 cases), ectopicACTH syndrome (20 cases), or primary adrenal disease (11 cases), demonstrating a sensitivity and specificity of $100 \%$ for this method. It is important to underscore the fact that such sensitivities and specificities are highly operator dependent - extensive experience is an important variable.

Catheterization of each of the inferior petrosal sinuses is performed and ACTH levels in each are taken simultaneously with a peripheral level prior to and following administration of $100 \mu \mathrm{g} \mathrm{CRH} .{ }^{35} \mathrm{It}$ is important to slowly aspirate venous blood over 60 seconds to help prevent retrograde venous flow. Most often, two post-CRH levels are measured-one between 2 and 3 minutes after CRH infusion and another between 5 and 6 minutes after infusion. If the ratio of either right or left inferior petrosal sinus to peripheral ACTH levels is greater than two prior to CRH stimulation or greater than three following the infusion, the test is exceedingly suggestive of Cushing disease. ${ }^{35}$ The utility of CRH stimulation lies in the fact that ACTH secretion may be pulsatile in patients with Cushing disease, ${ }^{47}$ requiring "unveiling" of the pulse to underscore a pituitary source of excess ACTH. Intuitively, patients with normal hypothalamic-pituitary-adrenal axes and pseudo-Cushing syndrome may have elevated petrosal sinus/peripheral ACTH ratios, particularly after CRH stimulation, underscoring the necessity of earlier testing to rule out these conditions.

Although the exceptional specificity of inferior petrosal sinus sampling for differentiating Cushing disease from ectopic ACTH syndrome has come under little scrutiny from experienced investigators, the authors of subsequent studies have revealed sensitivities of 92 to $96 \%$. 320 These imperfect false-negative rates have led to attempts to further stimulate pituitary ACTH secretion by the addition of desmopressin, an ACTH secretagogue. While some ectopic $\mathrm{ACTH}$-producing neoplasms are known to express V2 receptors, ${ }^{45}$ the investigators of a recent study involving 54 patients who received CRH and desmopressin (10 $\mu \mathrm{g}$ intravenously) stimulation for inferior petrosal sinus sampling reported a sensitivity of $98 \%$ while retaining a specificity of $100 \%$ for diagnosing Cushing disease. ${ }^{46}$ In another study, authors showed that normalizing the inferior petrosal sinus/peripheral ACTH ratio by dividing by the inferior petrosal sinus to peripheral prolactin level can improve the sensitivity of the test to $100 \%$; all 47 patients in the study with Cushing disease had ratios greater than 0.8, whereas all patients with the ectopic ACTH syndrome had ratios less than $0.6 .^{10}$ This result underscores one likely origin of the imperfect sensitivity of inferior petrosal sinus sampling: anomalous venous drainage. Venography prior to sampling can help reveal such drainage in patients. Indeed, the authors of one study showed an improvement in the sensitivity of inferior petrosal sinus sampling (from 94 to $98 \%$ ) when patients with abnormal venous drainage were exclud- ed. ${ }^{17}$ In another study, a ratio greater than 1.4 between inferior petrosal sinus ACTH levels correctly allowed lateralization of the lesion in 12 of 14 patients with symmetrical drainage but only four of nine patients with asymmetrical drainage (essentially no different from guessing). ${ }^{27}$ Another group reported an accuracy of $83 \%$ in distinguishing the side of the adenoma when a difference in ACTH level greater than 1.4 between the two sinuses existed. ${ }^{19} \mathrm{Al}$ though sampling the cavernous sinuses as an alternative to the inferior petrosal sinuses for localizing the adenoma and possibly improving diagnostic sensitivity seems intuitive, evidence has thus far shown no significant improvement compared with petrosal sinus sampling for lateralizing the lesion and diagnosing Cushing disease. . $^{6,24}$

Inferior petrosal sinus sampling is quite invasive and expensive (often \$2500-5000) and thus cannot be recommended for all patients with suspected Cushing disease. Furthermore, the success of the catheterization procedure is highly operator dependent, and documented serious complications include brainstem injury $(0.2 \%),{ }^{32}$ sixth nerve palsy (one in 166 patients in one study), ${ }^{23}$ and venous thromboembolism. ${ }^{34}$ Insertion-site hematomas occur in 3 to $4 \%$ of patients. ${ }^{31,32}$

Serious complications may be limited by employing internal jugular venous sampling as an alternative to inferior petrosal sinus sampling. As ACTH levels are expected to be diluted, the authors of one study used a cutoff ratio of 1.7 before CRH and 2.0 after CRH stimulation, revealing a $100 \%$ specificity and $83 \%$ sensitivity for this method in diagnosing Cushing disease. ${ }^{17}$ The relative simplicity and safety of this approach, coupled with its exceptional specificity, make it an attractive alternative for centers less skilled at performing inferior petrosal sinus sampling.

\section{Conclusions}

The diagnosis of Cushing disease can be efficiently confirmed by first establishing a diagnosis of Cushing syndrome via elevated 11 p.m. salivary cortisol levels. Con-

firmatory tests include 24-hour UFC levels and/or low-dose dexamethasone suppression tests. Patients with repeatedly equivocal results should be reevaluated after several months or undergo a CRH-stimulation test following low-dose dexamethasone suppression to help rule out pseudo-Cushing states. Low serum ACTH levels then distinguish primary adrenal hypercortisolism from Cushing disease and ectopic ACTH syndrome. A CRH stimulation test can be performed to clarify the underlying disease in patients with equivocal serum ACTH levels. Once ACTHdependent hypercortisolemia is detected, MR imaging of the pituitary can be performed to detect a pituitary neoplasm. Normal MR imaging results or those revealing noncharacteristic small pituitary lesions should be followed up with inferior petrosal sinus sampling and then imaging ( ${ }^{111}$ In-labeled pentetreotide scanning followed by CT and/or MR imaging of the neck, chest, and abdomen) if necessary to detect sources of ectopic ACTH. Modern modifications to the inferior petrosal sinus sampling procedure include the addition of desmopressin to CRH to further improve sensitivity of the test or alternatively measuring internal jugular ACTH levels, a far less invasive approach that retains specificity with a fall in sensitivity to $83 \% .^{17,46}$ 


\section{B. A. Gross et al.}

\section{Acknowledgments}

We thank Dr. Walter A. Stoller and Jessica Kazmier for their thoughtful contributions to this manuscript.

\section{References}

1. Aron DC, Raff H, Findling JW: Effectiveness versus efficacy: the limited value in clinical practice of high dose dexamethasone suppression testing in the differential diagnosis of adrenocorticotropin-dependent Cushing's syndrome. J Clin Endocrinol Metab 82:1780-1785, 1997

2. Avgerinos PC, Yanovski JA, Oldfield EH, Nieman LK, Cutler GB Jr: The metyrapone and dexamethasone suppression tests for the differential diagnosis of the adrenocorticotropin-dependent Cushing syndrome: a comparison. Ann Intern Med 121: 318-327, 1994

3. Bonelli FS, Huston J III, Carpenter PC, Erickson D, Young WF Jr, Meyer FB: Adrenocorticotropic hormone-dependent Cushing's syndrome: sensitivity and specificity of inferior petrosal sinus sampling. AJNR Am J Neuroradiol 21:690-696, 2000

4. Boscaro M, Barzon L, Sonino N: The diagnosis of Cushing's syndrome: atypical presentations and laboratory shortcomings. Arch Intern Med 160:3045-3053, 2000

5. Corcuff JB, Tabarin A, Rashedi M, Duclos M, Roger P, Ducassou D: Overnight urinary free cortisol determination: a screening test for the diagnosis of Cushing's syndrome. Clin Endocrinol (Oxf) 48:503-508, 1998

6. Doppman JL, Nieman LK, Chang R, Yanovski J, Cutler GB Jr, Chrousos GP, et al: Selective venous sampling from the cavernous sinuses is not a more reliable technique than sampling from the inferior petrosal sinuses in Cushing's syndrome. J Clin Endocrinol Metab 80:2485-2489, 1995

7. Duclos M, Corcuff JB, Pehourcq F, Tabarin A: Decreased pituitary sensitivity to glucocorticoids in endurance-trained men. Eur J Endocrinol 144:363-368, 2001

8. Duclos M, Corcuff JB, Roger P, et al: The dexamethasone-suppressed corticotrophin-releasing hormone stimulation test in anorexia nervosa. Clin Endocrinol (Oxf) 51:725-731, 1999

9. Ezzat S, Asa SL, Couldwell, WT, Barr CE, Dodge WE, Vance ML, et al: The prevalence of pituitary adenomas: a systematic review. Cancer 101:613-619, 2004

10. Findling JW, Kehoe ME, Raff H: Identification of patients with Cushing's disease with negative pituitary adrenocorticotropin gradients during inferior petrosal sinus sampling: prolactin as an index of pituitary venous effluent. J Clin Endocrinol Metab 89: 6005-6009, 2004

11. Findling JW, Raff H: Cushing's Syndrome: important issues in diagnosis and management. J Clin Endocrinol Metab 91: 3746-3753, 2006

12. Findling JW, Raff H: Diagnosis and differential diagnosis of Cushing's syndrome. Endocrinol Metab Clin North Am 30: 729-747, 2001

13. Findling JW, Raff H, Aron DC: The low-dose dexamethasone suppression test: a reevaluation in patients with Cushing's syndrome. J Clin Endocrinol Metab 89:1222-1226, 2004

14. Gold PW, Loriaux DL, Roy A, Kling MA, Calabrese JR, Kellner $\mathrm{CH}$, et al: Responses to corticotropin-releasing hormone in the hypercortisolism of depression and Cushing's disease. Pathophysiologic and diagnostic implications. N Engl J Med 314: 1329-1335, 1986

15. Graham SD Jr: Critical assessment of prostate cancer staging. Cancer 70 (1 Suppl):269-274, 1992

16. Hall WA, Luciano MG, Doppman JL, Patronas NJ, Oldfield EH: Pituitary magnetic resonance imaging in normal human volunteers: occult adenomas in the general population. Ann Intern Med 120:817-820, 1994

17. Ilias I, Chang R, Pacak K, Oldfield EH, Wesley R, Doppman J, et al: Jugular venous sampling: an alternative to petrosal sinus sam- pling for the diagnostic evaluation of adrenocorticotropic hormone-dependent Cushing's syndrome. J Clin Endocrinol Metab 89:3795-3800, 2004

18. Invitti C, Pecori Giraldi F, de Martin M, Cavagnini F: Diagnosis and management of Cushing's syndrome: results of an Italian multicentre study. Study Group of the Italian Society of Endocrinology on the Pathophysiology of the Hypothalamic-PituitaryAdrenal Axis. J Clin Endocrinol Metab 84:440-448, 1999

19. Kaltsas GA, Giannulis MG, Newell-Price JD, Dacie JE, Thakkar C, Afshar F, et al: A critical analysis of the value of simultaneous inferior petrosal sinus sampling in Cushing's disease and the occult ectopic adrenocorticotropin syndrome. J Clin Endocrinol Metab 84:487-492, 1999

20. Ketkar MB, Reznik G, Mohr U: Pathological alterations in Syrian golden hamster lungs after passive exposure to cigarette smoke. Toxicology 7:265-273, 1977

21. Krenning EP, Kwekkeboom DJ, Bakker WH, Breeman WA, Kooij PP, Oei HY, et al: Somatostatin receptor scintigraphy with [111In-DTPA-D-Phe1]-and [123I-Tyr3]-octreotide: the Rotterdam experience with more than 1000 patients. Eur J Nucl Med 20: 716-731, 1993

22. Lacroix A, Ndiaye N, Tremblay J, Hamet P: Ectopic and abnormal hormone receptors in adrenal Cushing's syndrome. Endocr Rev 22:75-110, 2001

23. Lefournier V, Gatta B, Martinie M, Vasdev A, Tabarin A, Bessou $P$, et al: One transient neurological complication (sixth nerve palsy) in 166 consecutive inferior petrosal sinus samplings for the etiological diagnosis of Cushing's syndrome. J Clin Endocrinol Metab 84:3401-3402, 1999

24. Liu C, Lo JC, Dowd CF, Wilson CB, Kunwar S, Aron DC, et al: Cavernous and inferior petrosal sinus sampling in the evaluation of ACTH-dependent Cushing's syndrome. Clin Endocrinol (Oxf) 61:478-486, 2004

25. Lufkin EG, Wahner HW, Bergstralh EJ: Reversibility of steroidinduced osteoporosis. Am J Med 85:887-888, 1988

26. Malchoff CD, Orth DN, Abboud C, Carney JA, Pairolero PC, Carey RM: Ectopic ACTH syndrome caused by a bronchial carcinoid tumor responsive to dexamethasone, metyrapone, and corticotropin-releasing factor. Am J Med 84:760-764, 1988

27. Mamelak AN, Dowd CF, Tyrrell JB, McDonald JF, Wilson CB: Venous angiography is needed to interpret inferior petrosal sinus and cavernous sinus sampling data for lateralizing adrenocorticotropin-secreting adenomas. J Clin Endocrinol Metab 81: 475-481, 1996

28. Mampalam TJ, Tyrrell JB, Wilson CB: Transsphenoidal microsurgery for Cushing disease. A report of 216 cases. Ann Intern Med 109:487-493, 1988

29. Mengden T, Hubmann P, Muller J, Greminger P, Vetter W: Urinary free cortisol versus 17-hydroxycorticosteroids: a comparative study of their diagnostic value in Cushing's syndrome. Clin Investig 70:545-548, 1992

30. Mericq MV, Cutler GB Jr: High fluid intake increases urine free cortisol excretion in normal subjects. J Clin Endocrinol Metab 83:682-684, 1998

31. Miller DL, Doppman JL: Petrosal sinus sampling: technique and rationale. Radiology 178:37-47, 1991

32. Miller DL, Doppman JL, Peterman SB, Nieman LK, Oldfield EH, Chang R: Neurologic complications of petrosal sinus sampling. Radiology 185:143-147, 1992

33. Nieman LK, Chrousos GP, Oldfield EH, Avgerinos PC, Cutler GB Jr, Loriaux DL: The ovine corticotropin-releasing hormone stimulation test and the dexamethasone suppression test in the differential diagnosis of Cushing's syndrome. Ann Intern Med 105: $862-867,1986$

34. Obuobie K, Davies JS, Ogunko A, Scanlon MF: Venous thromboembolism following inferior petrosal sinus sampling in Cushing's disease. J Endocrinol Invest 23:542-544, 2000

35. Oldfield EH, Doppman JL, Nieman LK, Chrousos GP, Miller DL, Katz DA, et al: Petrosal sinus sampling with and without corti- 
cotropin-releasing hormone for the differential diagnosis of Cushing's syndrome. N Engl J Med 325:897-905, 1991

36. Orth DN: Cushing's syndrome. N Engl J Med 332:791-803, 1995

37. Papanicolaou DA, Mullen N, Kyrou I, Nieman LK: Nighttime salivary cortisol: a useful test for the diagnosis of Cushing's syndrome. J Clin Endocrinol Metab 87:4515-4521, 2002

38. Papanicolaou DA, Yanovski JA, Cutler GB Jr, Chrousos GP, Nieman LK: A single midnight serum cortisol measurement distinguishes Cushing's syndrome from pseudo-Cushing states. J Clin Endocrinol Metab 83:1163-1167, 1998

39. Putignano P, Toja P, Dubini A, Pecori Giraldi F, Corsello SM, Cavagnini F: Midnight salivary cortisol versus urinary free and midnight serum cortisol as screening tests for Cushing's syndrome. J Clin Endocrinol Metab 88:4153-4157, 2003

40. Raff H, Findling JW: A physiologic approach to diagnosis of the Cushing syndrome. Ann Intern Med 138:980-991, 2003

41. Raff H, Raff JL, Findling JW: Late-night salivary cortisol as a screening test for Cushing's syndrome. J Clin Endocrinol Metab 83:2681-2686, 1998

42. Ross EJ, Linch DC: Cushing's syndrome-killing disease: discriminatory value of signs and symptoms aiding early diagnosis. Lancet 2:646-649, 1982

43. Selvais P, Donckier J, Buysschaert M, Maiter D: Cushing's disease: a comparison of pituitary corticotroph microadenomas and macroadenomas. Eur J Endocrinol 138:153-159, 1998

44. Tremble JM, Buxton-Thomas M, Hopkins D, Kane P, Bailey D, Harris PE: Cushing's syndrome associated with a chemodectoma and a carcinoid tumor. Clin Endocrinol (Oxf) 52:789-793, 2000

45. Tsagarakis S, Tsigos C, Vasiliou V, Tsiotra P, Kaskarelis J, Sotiropoulou C, et al: The desmopressin and combined CRH-desmopressin tests in the differential diagnosis of ACTH-dependent Cushing's syndrome: constraints imposed by the expression of V2 vasopressin receptors in tumors with ectopic ACTH secretion. J Clin Endocrinol Metab 87:1646-1653, 2002
46. Tsagarakis S, Vassiliadi D, Kaskarelis IS, Komninos J, Souvatzoglou E, Thalassinos N: The application of the combined corticotropin-releasing hormone plus desmopressin stimulation during petrosal sinus sampling is both sensitive and specific in differentiating patients with Cushing's disease from patients with the occult ectopic adrenocorticotropin syndrome. J Clin Endocrinol Metab 92:2080-2086, 2007

47. van den Berg G, Frolich M, Veldhuis JD, Roelfsema F: Combined amplification of the pulsatile and basal modes of adrenocorticotropin and cortisol secretion in patients with Cushing's disease: evidence for decreased responsiveness of the adrenal glands. J Clin Endocrinol Metab 80:3750-3757, 1995

48. Viardot A, Huber P, Puder JJ, Zulewski H, Keller U, Muller B: Reproducibility of nighttime salivary cortisol and its use in the diagnosis of hypercortisolism compared with urinary free cortisol and overnight dexamethasone suppression test. J Clin Endocrinol Metab 90:5730-5736, 2005

49. Yaneva M, Mosnier-Pudar H, Dugue MA, Grabar S, Fulla Y, Bertagna X: Midnight salivary cortisol for the initial diagnosis of Cushing's syndrome of various causes. J Clin Endocrinol Metab 89:3345-3351, 2004

50. Yanovski JA, Cutler GB Jr, Chrousos GP, Nieman LK: Corticotropin-releasing hormone stimulation following low-dose dexamethasone administration. A new test to distinguish Cushing's syndrome from pseudo-Cushing's states. JAMA 269: 2232-2238, 1993

Manuscript received June 15, 2007.

Accepted July 24, 2007.

Address reprint requests to: Bradley Gross, B.S., 244 East Pearson Street \#310, Chicago, Illinois 60611. b-gross@md. northwestern.edu. 